\title{
Disponibilidad de luz bajo dosel en rodales de Abies religiosa
}

\section{Understory light availability in stands of Abies religiosa}

\author{
Pedro Antonio Plateros-Gastélum!, Valentín José Reyes-Hernández*, Alejandro Velázquez-Martínezl, \\ Patricia Hernández-de la Rosa' y Gisela Virginia Campos-Ángeles²
}

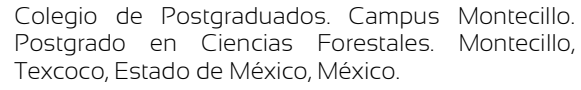

* Autor de correspondencia. vreyes@colpos.mx de Estudios de Postgrado e Investigación. Xoxocotlán, Oaxaca, México.

\section{RESUMEN}

La disponibilidad de luz en los bosques es uno de los principales factores que influyen en el establecimiento y desarrollo de especies vegetales bajo el dosel forestal. A fin de caracterizar el ambiente lumínico bajo el dosel de Abies religiosa (Kunth) Schltdl. et Cham., así como la estructura del dosel y su relación con la diversidad vegetal a nivel del sotobosque, se establecieron sitios de muestreo en los cuales se colectó información para evaluar atributos del rodal como área basal, densidad y diámetro cuadrático. Además, se determinaron, mediante fotografías digitales hemisféricas, los parámetros estructurales del dosel, índice de área foliar, fracción de apertura del dosel e índice de transmisión de luz; los parámetros lumínicos bajo el dosel: radiación directa y difusa, frecuencia, distribución de haces de luz, parches de luz, claros de luz y claros; duración media acumulada diaria de haces de luz y duración promedio de un haz de luz. Se determinó la relación existente entre las variables de estudio mediante regresión lineal simple y de asociación de estas a partir del coeficiente de correlación de Pearson. Los resultaron mostraron relaciones significativas entre parámetros estructurales del dosel $(\phi<$ 0.001) y parámetros lumínicos; mientras que las relaciones de parámetros de estructura del rodal y parámetros lumínicos $(p<0.05)$ tuvieron una menor correlación $(r \approx 0.50)$. La fracción de apertura del dosel fue el mejor predictor para el índice de área foliar, radiación directa y difusa disponible en el sotobosque, así como para el índice de transmisión de luz del dosel. La variabilidad del régimen de luz bajo dosel fue mejor explicada por los parámetros de la estructura que por las características estructurales del rodal.

PALABRAS CLAVE: cobertura del dosel, fotografías hemisféricas, haces de luz, índice de área foliar, oyamel, sotobosque.

\section{ABSTRACT}

The availability of light is one of the main factors that influences the establishment and development of plant species in the forest understory. In order to characterize the light environment and canopy structure, and their relationships with understory plant diversity, sampling sites were established in pure Abies religiosa (Kunth) Schltdl. et Cham. stands in Aquixtla, Puebla. In these sites, information useful to evaluate stands characteristics, namely basal area, tree density, and quadratic mean diameter was collected. Also, canopy structural characteristics, in particular, leaf area index, canopy opening fraction, and light transmission index, were estimated from hemispherical photographs taken onsite and analysed with the software GLI ${ }^{\circledR}$. Understory light environment indicators were also estimated, namely direct and diffuse radiation, sunflecks distribution and frequency, sunpatches, sungaps, and clearings, as well as cumulative average daily sunflecks and average sunflecks duration. Relationships among the variables estimated were determined with Pearson's correlation coefficient and with simple linear regression. Results showed a significant and strong relationship between canopy structure and solar radiation parameters $(p<0.001)$, while stand structure and light parameters $(p<0.05)$ showed a low correlation $(r \approx$ 0.50). Canopy opening fraction was the most powerful explanatory variable for leaf area index, direct and diffuse radiation available in the understorey, as well as for canopy light transmission rate. The variability of the understory light regime for these stands was better explained by canopy structure parameters than by stand structural characteristics.

KEYWORDS: canopy cover, hemispherical photography, sunflecks, leaf area index, oyamel fir, understorey plants. 


\section{INTRODUCCIÓN}

La radiación solar disponible en el sotobosque es uno de los principales factores que influyen en el establecimiento y desarrollo de vegetación bajo el dosel forestal (Lieffers, Messier, Stadt, Gendron y Comeau, 1999; Macdonald y Fenniak, 2007; Hu, Yan, Wu y Li, 2010). La radiación solar, tanto directa como difusa, que incide en un determinado lugar tiene influencia sobre los procesos fisiológicos, morfológicos y reproductivos de los organismos presentes bajo el dosel forestal, así como sobre los procesos químicos y físicos del ecosistema (Hardy et al., 2004; Promis, Schindler, Reif y Cruz, 2009; Sonohat, Balandier y Ruchaud, 2004). El balance entre la radiación solar incidente en el dosel y en el sotobosque, así como su distribución, dependerán de la transmisión e intercepción de la radiación solar por y a través de la cubierta vegetal (Webster, Rutter, Zahner y Jonas, 2016), la cual está determinada por la densidad, tamaño y distribución de las copas de los árboles (i.e. su estructura) (Canham y Burbank, 1994; Hardy et al., 2004; Jennings, Brown y Sheil, 1999). De esta forma, es posible establecer una relación respecto de la cantidad y heterogeneidad de la radiación solar como resultado de los patrones espaciales del dosel (Canham y Burbank, 1994; Denny y Nielsen, 2017). Con base en lo anterior, el modelo de Beer-Lambert-Bouguer ha sido modificado para ser usado en el dosel forestal, considerando que la cantidad de luz transmitida a través de este dependerá de la densidad de su estructura, y es descrito como un medio turbio con elementos distribuidos de manera aleatoria (Larsen y Kershaw, 1996; Monsi y Saeki, 2005).

En este estudio, se evaluó al dosel forestal por medio del uso de fotografías hemisféricas $(\mathrm{FH})$, dado que la estructura del dosel afecta directamente la cantidad, calidad, distribución espacial y temporal de la luz dentro del bosque, además de que influye en la presencia o ausencia de repoblación, así como en el establecimiento y desarrollo de diversas especies de plantas a nivel del sotobosque (Macdonald y Fenniak, 2007). La estructura del dosel también modifica las condiciones ambientales y edáficas (e.g. microclima, disponibilidad de nutrientes, $\mathrm{pH}$ ), así como las funciones ecofisiológicas de los organismos en el bosque
(Jennings et al., 1999). El uso de FH se ha generalizado como una herramienta para caracterizar la estructura del dosel forestal, así como para estimar regímenes de radiación solar presente en bosques y selvas (Nobis y Hunziker, 2005; Seidel, Fleck, Leuschner y Hammett, 2011). El empleo de las FH se basa en el supuesto teórico de la interacción entre la radiación solar y el dosel (Canham y Burbank, 1994; Frazer, Canham y Lertzman, 1999; Schleppi y Paquette, 2017), de tal manera que es posible calcular el valor del coeficiente de extinción de luz (k), a partir de correlaciones entre el ángulo de inclinación de las hojas, la cobertura del dosel (Pekin y Macfarlane, 2009) y el índice de área foliar (Chianucci y Cutini, 2013; Schleppi y Paquette, 2017) a partir de FH. De igual forma, mediante $\mathrm{FH}$ es posible obtener un registro detallado de la distribución espacial, tamaño y forma de los claros del dosel en función del ángulo cenital (Gonsamo, D’odorico y Pellikka, 2013), permitiendo el cálculo del índice de transmisión de luz (GLI), el cual es relativamente similar al índice de luz en claros propuesto por Canham (1988) (Frazer et al., 1999). El procesamiento y análisis de FH digitales, a través de software especializado, comprende la transformación de la posición de cada pixel en coordenadas angulares, la discriminación entre pixeles sin obstrucción (cielo) y obstruidos (vegetación) y el cómputo de la distribución de brillo del cielo. Esta información, de manera combinada o individual, dará como resultado estimaciones de parámetros de la estructura del dosel, índices de transmisión de radiación, frecuencia y duración de haces de luz, así como proporción de luz directa y difusa (Frazer et al., 1999).

Desde la perspectiva de la silvicultura, con este estudio se busca estimar la transmisión de radiación solar en rodales de Abies religiosa (Kunth) Schltdl. et Cham., a partir de características dasométricas, de la estructura del dosel (apertura del dosel) y del rodal (área basal o densidad), Esto permitiría predecir la radiación incidente directa y difusa, a nivel del sotobosque, y proponer tratamientos silvícolas que ayuden a alcanzar diversos objetivos relacionados con los procesos de repoblación, supervivencia, desarrollo, sucesión forestal y diversidad (Hale, Edwards, Mason, Price y Peace, 2009); ya que la radiación solar transmitida a través 
del dosel, es un factor ambiental crucial en los procesos descritos.

\section{OBJETIVOS}

Analizar los efectos del dosel forestal en la transmisión de radiación solar al sotobosque en rodales puros de Abies Religiosa y evaluar si la estructura del dosel, así como parámetros a nivel del rodal, permiten explicar la variación de la radiación solar bajo el dosel.

\section{MATERIALES Y MÉTODOS}

\section{Área de estudio}

El presente estudio se realizó en el conjunto predial Reserva Forestal "El Manantial" S.C. ubicado en la región de la "Sierra Norte" del estado de Puebla, entre los 1942'27.4" y 1944'37.6" de latitud norte y los 98 $00^{\prime} 43.9^{\prime \prime}$ y $97^{\circ} 58^{\prime} 56.5^{\prime \prime}$ de longitud oeste dentro de la subprovincia fisiográfica Lagos y Volcanes del Anáhuac, como parte de la provincia Eje Neovolcánico, con presencia de pendientes de entre $20 \%$ y $60 \%$ y altitudes desde los $2650 \mathrm{~m}$ hasta los 3178 m (Castaños y Castro, 2014). Predominan en el área los suelos de tipo Andosol (Organización de las Naciones Unidas para la Alimentación y la Agricultura - Organización de las Naciones Unidas para la Educación, la Ciencia y la Cultura [FAO-Unesco], 1998). Como resultado del relieve, altitud e influencia de los vientos alisios del Golfo de México, se identifican dos tipos de clima, $\mathrm{C}\left(\mathrm{w}_{1}\right)$ por debajo de los $3000 \mathrm{~m}$ de altitud y $\mathrm{C}\left(\mathrm{w}_{2}\right)$ por arriba de dicha cota altitudinal, difiriendo únicamente en la cantidad de precipitación anual (Castaños y Castro, 2014; García, 1964). La vegetación corresponde a masas mezcladas de pinos (Pinus patula, P. pseudostrobus, P. ayacabuite var. veitchii, P. rudis y $P$. teocote) y oyamel (Abies religiosa) en diferentes proporciones y masas puras de pino ( $P$. patula) así como de oyamel (A. religiosa) (Castaños y Castro, 2014).

\section{Sitios de muestreo}

Se establecieron 16 unidades de muestreo circulares de 500 $\mathrm{m}^{2}($ radio $=12.61 \mathrm{~m})\left(\mathrm{t}_{0.05}\right.$ con $7 \mathrm{~g} .1, \mathrm{~s}^{2}=43.02$ y estimador de la media $=24.47)($ Freese, 1976), que representan una intensidad de muestreo de 2.3\% (Schreuder, Ernst y
Ramírez-Maldonado, 2004) del área que cubren las masas puras de oyamel en el predio donde se obtuvieron los datos dasométricos del arbolado (Castaños y Castro, 2014). Las variables dasométricas medidas fueron diámetro normal (cm) y altura total (m) y se registró la especie a la que pertenecía cada individuo con diámetro normal $\geq 5.0 \mathrm{~cm}$ (Bonham, 2013). Se establecieron relaciones lineales entre parámetros como diámetro cuadrático $(d c)$, área basal $(G)$ y densidad $(N)$ con el régimen de luz presente bajo el dosel (Hale et al., 2009; Comeau, 2001). Se utilizaron FH para estimar el porcentaje de claros, índice de área foliar y radiación trasmitida a través del dosel, la FH mide la fracción de huecos en múltiples ángulos a zenit (Seidel et al., 2011). Dentro de cada unidad de muestreo, con una distribución espacial al centro, norte, sur, este y oeste, se ubicaron cinco puntos (cuatro a una distancia del centro de $8.92 \mathrm{~m}$ ) para realizar la captura de fotografías hemisféricas y estimar la radiación solar además de la fracción de cielo visible (Nackaerts, Coppin, Muys y Hermy, 2000), a fin de establecer su relación lineal con parámetros del rodal (Chazdon, Pearcy, Lee y Fetcher, 1996).

\section{Obtención de imágenes hemisféricas}

Cada una de las fotografías hemisféricas fue capturada con una cámara digital Canon ${ }^{\circledR}$ EOS SL1 APS-C sensor CMOS de 18 megapixeles, provista de una lente hemisférica "ojo de pescado" (Fisheye) Rokinon ${ }^{\circledR} 8 \mathrm{~mm}$ F3.5 HD y un nivel de burbuja Polaroid ${ }^{\circledR}$ de doble eje. El equipo se montó en un trípode para ubicar el lente a una altura de $1.30 \mathrm{~m}$ sobre el nivel del suelo, y facilitar su nivelación horizontal y orientación hacia el norte. Para capturar las imágenes se empleó el protocolo estándar para fotografías hemisféricas usadas en la estimación de la estructura del dosel (Zhang, Chen y Miller, 2005), el cual se basa en la determinación del grado de exposición a la luz, para lo cual se controla la apertura del lente y la velocidad de obturación (Leblanc, Chen, Fernandes, Deering y Conley, 2005). El valor de apertura del lente se determinó en f5.6, una velocidad de obturación de 1/125 segundos y a una sensibilidad ISO 400 (1/4 de segundo). La calidad de las imágenes capturadas fue de 5184 píxeles $\times 3456$ píxeles con una resolución tanto 
vertical como horizontal de 138 puntos por centímetro (350 puntos por pulgada) en formato JPEG a color y RAW. Se obtuvo un total de 80 fotografías de todos los sitios de muestreo, esto es, cinco fotografías por sitio.

\section{Procesamiento y análisis digital de imágenes}

Métodos ópticos indirectos, como la FH, se sustentan en mediciones de la transmisión de radiación a través del dosel, para lo cual aplican la ley de Beer-Lambert-Bouguer (Ecuación 1). Esta ley considera la cantidad total de radiación interceptada por el dosel y depende de la radiación incidente, de la estructura del dosel y de las propiedades ópticas del mismo. Para estimar la transferencia de radiación solar a través del dosel forestal, en este estudio, se ha adoptado y modificado dicho modelo para describir la atenuación de la radiación solar a través de un dosel horizontal y homogéneo (Monsi y Saeki, 2005; Forrester et al., 2014).

$$
K_{\text {bajo dosel }}=K_{\text {sobre dosel }} e^{-f}
$$

Donde $K$ es la radiación entrante o incidente arriba y bajo el dosel, $f$ es el espesor del dosel, el cual dependerá del índice de área foliar y de variables como la fracción de apertura del dosel y el ángulo de incidencia de la radiación solar, mientras que $e$ es el número de Euler (Hardy et al., 2004).

El procesamiento y análisis de las FH capturadas se realizó con el software Gap Light Analyzer ${ }^{\circledR}$ (GLA) v.2.0 conforme al procedimiento descrito en el manual del usuario (Frazer et al., 1999; Nobis y Hunziker, 2005). Para el análisis de cada fotografía, durante la etapa de registro de cada imagen, se suministró información particular del sitio donde se realizó la captura de la imagen como latitud, longitud, altitud, exposición y pendiente; además, se estableció el período de análisis a considerar (365 días). Durante la etapa de configuración, previo a la clasificación de cada imagen, se proporcionaron algunos parámetros de ajuste definidos previamente por el usuario (Tabla 1) (Frazer et al., 1999). El índice de nubosidad se fijó en 0.5, que es adecuado para describir la nubosidad anual en
América del Norte (Frazer et al., 1999). El valor de la fracción espectral, es decir el porcentaje de radiación fotosintéticamente activa, corresponde aproximadamente a $45 \%$ de la radiación anual incidente en una superficie horizontal (Hardy et al., 2004; Lieffers et al., 1999; Papaioannou, Nikolidakis, Asimakopoulus y Retalis,1996). La fracción de radiación directa incidente, para la mayor parte de las regiones del norte del continente, es de aproximadamente $50 \%$ de la radiación global anual (Beaudet et al., 2011; Canham y Burbank, 1994; Frazer et al., 1999). El coeficiente de transmisión bajo cielo claro, para la mayor parte de las regiones libres de polvo se encuentra entre $0.6 \mu \mathrm{m}$ y $0.7 \mu \mathrm{m}$ (Frazer et al., 1999; Gates, 1980), por lo que en este trabajo se utilizó un valor medio de $0.65 \mu \mathrm{m}$ (Beaudet et al., 2011; Scanga, 2014); si bien el valor de la constante solar se ha calculado en $1360.8 \mathrm{~W} \cdot \mathrm{m}^{-2} \pm 0.5$ $\mathrm{W} \cdot \mathrm{m}^{2}$ (Kopp y Lean, 2011), en este estudio se empleó el valor recomendado en el manual del usuario de GLAC (Frazer et al., 1999; Schleppi y Paquette, 2017).

TABLA 1. Variables suministradas por el usuario para el análisis de las fotografías hemisféricas empleando el software GLAC.

\begin{tabular}{lr}
\hline Variable & \multicolumn{1}{c}{ Valor } \\
\hline Índice de nubosidad & 0.5 \\
Fracción del espectro electromagnético & 0.45 \\
Fracción de la radiación directa incidente & 0.5 \\
Coeficiente de transmisión bajo cielo claro $(\mu \mathrm{m})$ & 0.65 \\
Valor de la constante solar (W.m²) & 1367 \\
Intensidad del sol en condiciones de cielo nublado & UOC \\
\hline UOC = Universal Overcast Sky, el cual considera que en condiciones de \\
cielo nublado uniforme la radiación incidente es isotrópica (Schleppi y \\
Paquette, 2Ol7)
\end{tabular}

Por medio del software GLAC, se obtuvieron estimaciones de variables de estructura del dosel: fracción de apertura del dosel (FAD) e índice de área foliar (IAF) (Frazer, Fournier, Trofymow y Hall, 2001; Webster et al., 2016), además de estimadores de radiación solar en función de la radiación incidente por encima del dosel: radiación directa transmitida a través del dosel (TransDir) y luz difusa transmitida (TransDif). Adicionalmente, para describir la duración en minutos de la radiación solar que 
potencialmente podría alcanzar un punto en el sotobosque (Hu et al., 2010), se obtuvo: duración promedio acumulada de los haces de luz (DAS), duración media de un haz de luz (DPS) y frecuencia relativa de haces de luz (FRH) (Frazer et al., 1999). La distribución de frecuencia relativa de haces de luz, se realizó utilizando la clasificación propuesta por Smith y Berry (2013). Esta clasificación divide a los episodios de radiación solar en función de la duración e intensidad de las variaciones de radiación presentes tanto en el dosel forestal como en el sotobosque y se detalla a continuación: haz de luz o "sun-flecks" con una intensidad menor a $100 \%$ y duración menor a 8 minutos (SF); episodios con intensidades de $100 \%$ y duraciones mayores a 8 minutos como parche o mancha de luz "sun-patch" (SP), mayores a 60 minutos claro de luz “sun-gap” (SG) y aquellos mayores a 120 minutos como claros "clearing" (CL).

De igual forma, por medio del modelo básico de transmisión de luz a través de claros del software GLAC, se estimaron los porcentajes de radiación incidente directa, difusa y total transmitida a través de claros en el dosel hacia el sotobosque (Frazer et al., 1999), y se determinó el porcentaje de radiación transmitida, que en conjunto se denomina índice de transmisión de luz (GLI) (Frazer et al., 1999; Canham, 1988; Bartemucci, Messier y Canham, 2006). El GLI es relativamente similar al índice de luz en claros (Gap Light Index - GLI) (Ecuación 2) propuesto por Canham (1988), que especifica el porcentaje de radiación fotosintéticamente activa (RFA) incidente, transmitida a través de un claro del dosel hacia cualquier punto sobre el sotobosque durante un período determinado. Este índice permite relacionar, a pesar de la variación espacial y temporal de los niveles de luz incidente en el sotobosque, el tamaño y la forma de un claro con la transmisión RFA tanto directa como difusa a cualquier punto en particular dentro o fuera del claro.

$$
G L I=\left(T_{d i f} \cdot P_{d i f}+T_{d i r} \cdot P_{d i r}\right) \cdot 100
$$

Donde, $P_{\text {dif }}$ y $P$ dir son las proporciones de RFA incidente en la parte superior del dosel como radiación difusa $y$ radiación directa, respectivamente $\left(P_{d i f}=1-P_{d i r}\right) ; \mathrm{y} T_{d i f} \mathrm{y}$
$T_{\text {dir }}$ son las proporciones de radiación difusa y directa que son transmitidas a través de un claro en el dosel a un punto del sotobosque. Este índice toma valores desde 0, que es cuando no está definido un claro visible en el dosel, hasta un máximo de 100 que corresponde a un sitio en ausencia de dosel, o bien a cielo abierto (Canham, 1988; Bartemucci et al., 2006). Debido a que al incrementar la apertura del dosel (i.e. mayor presencia de claros), se incrementará el porcentaje de radiación tanto directa como difusa que será transmitido a través de este (Messier, Parent y Bergeron, 1998; Promis et al., 2009), se determinó la asociación entre los parámetros FAD y GLI mediante el coeficiente de correlación de Pearson.

\section{Análisis estadístico}

El análisis de las variables obtenidas se realizó con el paquete para computación y gráficos estadísticos $R^{\odot}$ (Venables y Smith, 2017), por medio del cual, para cada una de las variables de estructura del rodal y del dosel así como de radiación solar estimadas, se calcularon los valores medios, desviación estándar y coeficiente de variación (C.V.) por unidad muestral. Además, se realizaron análisis de correlación de Pearson entre las características estructurales y las variables de disponibilidad de luz bajo dosel, para después estimar asociaciones entre ellas por medio de análisis de regresión lineal simple (Ecuación 3).

$$
Y_{t}=\beta_{1}+B_{2} X_{t}+u_{t}
$$

Donde, $\beta_{1}$ es el intercepto teórico de la variable dependiente (Y) del modelo, $\beta_{2}$ es la pendiente teórica de la línea, $X$ la variable independiente que afecta a $Y$, mientras que $u$ es el error residual (Muenchen y Hilbe, 2010).

\section{Resultados}

$\mathrm{El}$ área basal $(G)$ de las unidades de muestreo se distribuyó en un intervalo de $22.64 \mathrm{~m}^{2}$ a $53.55 \mathrm{~m}^{2} \mathrm{ha}^{-1}$; mientras que el intervalo del diámetro cuadrático $(d c)$ fue entre $14.0 \mathrm{~cm} \mathrm{y}$ $35.0 \mathrm{~cm}$; la densidad $(N)$ presentó una distribución entre 460 y 1980 árboles por hectárea; la altura media entre los rodales fue entre $15.15 \mathrm{~m}$ y $23.97 \mathrm{~m}$ (Tabla 2). El análisis de correlación mostró la existencia de relaciones positivas 
Plateros-Gastélum et al. Disponibilidad de luz bajo dosel

TABLA 2. Valores promedio por unidad muestral de los parámetros de estructura del rodal, estructura del dosel, transmisión de luz a través del dosel y régimen de luz en rodales de Abies religiosa.

\begin{tabular}{|c|c|c|c|c|c|c|c|c|c|c|c|c|c|c|c|c|}
\hline $\begin{array}{c}\text { Parámetros/Unidad de } \\
\text { muestreo }\end{array}$ & 1 & 2 & 3 & 4 & 5 & 6 & 7 & 8 & 9 & 10 & 11 & 12 & 13 & 14 & 15 & 16 \\
\hline \multicolumn{17}{|l|}{ Estructura del rodal } \\
\hline $\begin{array}{l}\text { Diámetro medio cuadrático } \\
\left(d_{g}\right) \mathrm{cm}\end{array}$ & 21.8 & 22.0 & 30.7 & 26.6 & 19.6 & 34.9 & 29.4 & 28.4 & 21.6 & 34.2 & 30.2 & 34.2 & 24.5 & 14.0 & 15.2 & 18.0 \\
\hline Altura media $\left(\mathrm{Hm}_{\mathrm{m}}\right) \mathrm{m}$ & 20.17 & 18.39 & 21.89 & 21.02 & 17.86 & 23.56 & 22.50 & 22.15 & 18.48 & 21.52 & 22.17 & 23.97 & 20.93 & 13.86 & 12.15 & 16.16 \\
\hline Área basal (G) m².ha-1 & 38.87 & 37.66 & 34.12 & 35.70 & 36.96 & 44.08 & 40.75 & 48.19 & 29.58 & 53.55 & 34.46 & 49.69 & 35.02 & 32.20 & 22.64 & 29.72 \\
\hline Densidad (N) Ind.ha-1 & 1040 & 1000 & 460 & 640 & 1220 & 460 & 600 & 760 & 800 & 580 & 480 & 540 & 740 & 1980 & 1240 & 1160 \\
\hline \multicolumn{17}{|l|}{ Estructura del dosel } \\
\hline $\begin{array}{l}\text { Fracción de apertura del } \\
\text { dosel (FAD) }\end{array}$ & 0.23 & 0.22 & 0.24 & 0.36 & 0.24 & 0.34 & 0.31 & 0.37 & 0.44 & 0.38 & 0.41 & 0.35 & 0.31 & 0.29 & 0.23 & 0.19 \\
\hline $\begin{array}{l}\text { Índice de área foliar (IAF) } \\
\mathrm{m}^{2} \cdot \mathrm{m}^{-2}\end{array}$ & 1.68 & 1.78 & 1.69 & 1.11 & 1.63 & 1.28 & 1.30 & 1.09 & 0.87 & 1.13 & 1.01 & 1.19 & 1.35 & 1.36 & 1.69 & 1.89 \\
\hline \multicolumn{17}{|l|}{ Transmisión de luz } \\
\hline $\begin{array}{l}\text { Índice de transmisión de } \\
\text { luz (GLI) \% }\end{array}$ & 26.91 & 23.02 & 26.59 & 38.95 & 26.51 & 33.21 & 32.57 & 39.66 & 47.67 & 37.96 & 42.01 & 38.79 & 32.26 & 30.24 & 24.21 & 19.03 \\
\hline $\begin{array}{l}\text { Radiación directa } \\
\text { transmitida a través del } \\
\text { dosel (TransDir) }\end{array}$ & $5.04 a c$ & 4.15ab & 4.78ab & $6.86 a c$ & 4.78ab & $5.70 a c$ & $5.80 a c$ & $7.10 b c$ & $8.58 c$ & $6.77 a c$ & $7.23 \mathrm{bc}$ & $7.38 b c$ & $5.78 a c$ & $5.15 a c$ & $4.15 a b$ & $3.18 a$ \\
\hline $\begin{array}{l}\text { Radiación difusa } \\
\text { transmitida a través del } \\
\text { dosel (TransDif) }\end{array}$ & 4.47ab & 3.98ab & 4.62abc & $6.90 \mathrm{bd}$ & 4.59abc & $6.04 a d$ & 5.71ad & $6.92 b d$ & 8.27d & $6.65 b d$ & 7.61cd & 6.33ad & 5.62ad & $5.54 \mathrm{ad}$ & 4.40ab & 3.55a \\
\hline \multicolumn{17}{|l|}{ Dinámica de luz } \\
\hline $\begin{array}{l}\text { Duración media acumulada } \\
\text { de luz (DAS) min.dia-1 }\end{array}$ & 178.92 & 170.01 & 183.70 & 264.10 & 174.16 & 233.50 & 231.55 & 282.36 & 326.54 & 271.08 & 279.75 & 295.34 & 233.81 & 194.25 & 157.35 & 114.07 \\
\hline $\begin{array}{l}\text { Número de "sunflecks" por } \\
\text { día (NSD) }\end{array}$ & 33 & 36 & 32 & 26 & 28 & 39 & 33 & 33 & 32 & 43 & 23 & 30 & 38 & 40 & 37 & 19 \\
\hline $\begin{array}{l}\text { Duración promedio de haz } \\
\text { de luz (DPS) min. }\end{array}$ & 5.23 & 4.71 & 5.82 & 10.33 & 6.10 & 5.86 & 7.07 & 8.55 & 10.32 & 6.35 & 12.85 & 10.09 & 6.10 & 4.79 & 4.22 & 6.04 \\
\hline $\begin{array}{l}\text { Proporción de haces de luz } \\
\text { (SF) }\end{array}$ & 0.87 & 0.90 & 0.90 & 0.75 & 0.87 & 0.85 & 0.81 & 0.77 & 0.74 & 0.86 & 0.76 & 0.79 & 0.85 & 0.89 & 0.92 & 0.86 \\
\hline $\begin{array}{l}\text { Proporción de parches de } \\
\text { luz (SP) }\end{array}$ & 0.12 & 0.10 & 0.10 & 0.22 & 0.12 & 0.14 & 0.18 & 0.22 & 0.23 & 0.14 & 0.20 & 0.18 & 0.14 & 0.11 & 0.08 & 0.14 \\
\hline $\begin{array}{l}\text { Proporción de claros de luz } \\
\text { (SG) }\end{array}$ & 0.00 & 0.00 & 0.00 & 0.03 & 0.01 & 0.01 & 0.01 & 0.01 & 0.03 & 0.00 & 0.02 & 0.01 & 0.01 & 0.00 & 0.00 & 0.01 \\
\hline Proporción de claros (CL) & 0.00 & 0.00 & 0.01 & 0.00 & 0.00 & 0.00 & 0.00 & 0.00 & 0.01 & 0.00 & 0.03 & 0.01 & 0.00 & 0.00 & 0.00 & 0.00 \\
\hline
\end{tabular}

Unidades muestrales 1) Chichicaxtla Bis I, 2) Chichicaxtla Bis II, 3) Chichicaxtla I, 4) El Ocote I, 5) El Ocote II, 6) El Ocote III, 7) Los Corrales I, 8) Los Corrales II, 9) Los Corrales III, 1O) Los Corrales IV, 11) Los Corrales V , 12) Los Corrales VI, 13) Los Corrales VII, 14) Ocojala Sierra Mojada I, 15) Ocojala Sierra Mojada II, 16) Ocojala Sierra Mojada III. Valores con la misma Ietra para radiación transmitida, ya sea directa o difusa, son iguales de acuerdo a la prueba de Tukey con $p<0.05$, unidades en Mols.m².día'. 
significativas $(p<0.05)$ del diámetro cuadrático $(d c)$ con los parámetros FAD $(r=0.53)$, DAS $(r=0.59), \operatorname{TranDir}(r=$ $0.52)$ y GLI $(r=0.50)$ (Tabla 3). La relación de la densidad $(N)$ fue también significativa $(\phi<0.05)$ pero negativa con DAS $\left(R^{2}=29\right)$ y DPS $\left(R^{2}=0.27\right)$ (Fig. 1$)$. El resto de los parámetros de estructura del rodal, régimen y distribución de luz, mostraron correlaciones nulas o débiles $(p>0.05)$, lo cual contrasta con otros trabajos que señalan relaciones significativas negativas no lineales entre la radiación bajo el dosel y el área basal del rodal (Buckley, 1999; Ligot et al., 2014); en particular, entre la fracción de radiación difusa transmitida (Comeau, 2001) y la capacidad de transmisión de luz a través del dosel con el área basal (Sonohat et al., 2004).

La fracción de apertura del dosel (FAD) promedio $( \pm$ desviación estándar) fue de $0.3059 \pm 0.0946$, (C.V. = $30.92 \%$, máximo $=0.4792$ y mínimo $=0.1262)$; mientras que para el índice de transmisión de luz (GLI) el promedio fue de $32.47 \% \pm 10.65 \%$, con un valor mínimo de 10.84 , máximo de $53.48 \%$ y C.V. de $32.79 \%$. La relación entre la estructura del dosel y transmisión de luz puede ser explicada por medio de una regresión lineal simple entre el grado de apertura del dosel (FAD) y la cantidad de luz transmitida (GLI) a través de este (Fig. 2). El coeficiente de determinación para el modelo de regresión lineal fue de 0.95 (Tabla 3).

Los estadísticos para el índice de área foliar estimada a partir de las FH son los siguientes: media de $1.38 \mathrm{~m}^{2} \mathrm{~m}^{-2} \pm$ $0.41 \mathrm{~m}^{2} \mathrm{~m}^{-2}$ y valores máximo y mínimo de $2.38 \mathrm{~m}^{2} \mathrm{~m}^{-2} \mathrm{y}$ $0.76 \mathrm{~m}^{2} \mathrm{~m}^{-2}$, respectivamente (C.V. de 29.72\%). El IAF se estimó a partir de características del dosel y de transmisión de luz, por lo que muestra una correlación negativa con la luz difusa transmitida (TransDif) con valor de -0.97 , con la luz directa a través del dosel (TransDir) de -0.87 , fracción de apertura del dosel (FAD) de -0.97 y de -0.94 con el índice de transmisión de luz (GLI) (Tabla 3). La estimación del IAF muestra que la relación existente entre los parámetros TransDif, TransDir, FAD y GLI se ajusta a un modelo de tipo exponencial (Gower y Normanm, 1991), para cada uno de los parámetros analizados (Fig. 3), lo cual indica, que la transmisión de la luz hacia la parte baja del dosel disminuirá de manera exponencial al aumentar el área de intercepción (Chazdon y Pearcy, 1991; Hardy et al., 2004; LópezSandoval et al., 2015).

$\mathrm{El}$ análisis estadístico mostro diferencias significativas $(p<0.05)$ entre sitios para la radiación transmitida a través del dosel, tanto directa como difusa; de tal manera, que la radiación directa incidente en el sotobosque bajo un dosel con una fracción de apertura de 0.19, será aproximadamente $63 \%$ menor que la radiación incidente en el sotobosque bajo un dosel con una fracción de apertura de 0.44 . De igual forma, la radiación difusa incidente en el sotobosque se reducirá en alrededor de $57 \%$ en estas mismas condiciones de apertura del dosel (Tabla 2). Este patrón se explica dado que una mayor cobertura del dosel implica una mayor tasa de captura de radiación solar, expresado ello mediante el índice de transmisión de luz (GLI) (Marthews, Burslem, Phillips y Mullins, 2008; Messier et al., 1998; Promis et al., 2009).

Para la duración acumulada media de haces de luz (DAS), que describe el número de minutos de radiación directa potencial que podría recibir un sitio durante un día a lo largo de un año, se obtuvo un promedio de $224.4 \mathrm{~min}$ día ${ }^{-1} \pm 76.4$ min día ${ }^{-1}$, con un máximo de 377.8 min día ${ }^{-1}$ y un mínimo de 60.2 min día $^{-1}$ (C.V. = 34.04\%). La DAS se relacionó de manera positiva con $\mathrm{FAD}\left(\mathrm{R}^{2}=0.82, p<\right.$ $0.0001)$, con el índice de transmisión de luz (GLI) $\left(R^{2}=\right.$ $0.91, p<0.0001)$, y con la radiación directa transmitida (TransDir) $\left(R^{2}=0.93, p<0.0001\right)$ (Fig. 4).

La duración promedio de un haz de luz (DPS) es de $7.15 \mathrm{~min} \pm 2.88 \mathrm{~min}$, con un valor máximo de $18.26 \mathrm{~min}$, mínimo de $3.38 \mathrm{~min}$ y C.V. de $40.27 \%$ (Tabla 2). Es conveniente señalar que el ambiente lumínico bajo diferentes tipos de dosel forestal tiende a ser diferente (Chazdon y Pearcy, 1991; Chen, 2014; Smith y Berry, 2013). $\mathrm{El}$ análisis de regresión muestra que DPS se relaciona de manera positiva con la FAD $\left(R^{2}=0.49\right)$, con la transmisión de radiación a través del dosel (GLI) $\left(R^{2}=\right.$ $0.43)$, con TransDir $\left(R^{2}=0.54\right)$ (Fig. 5) y con TransDif $\left(R^{2}\right.$ $=0.52$ ), lo cual indica que con un incremento en cualesquiera de estos parámetros se incrementará la duración de los haces o destellos de luz bajo el dosel. La 
Plateros-Gastélum et al. Disponibilidad de luz bajo dosel

TABLA 3. Coeficientes de correlación de Pearson y nivel de significancia ( $p$-value) para diversos indicadores de estructura del rodal, dosel y distribución de luz bajo el dosel de Abies religiosa en Aquixtla, Puebla.

\begin{tabular}{|c|c|c|c|c|c|c|c|c|c|c|c|c|c|c|c|}
\hline & $G$ & dc & $\mathrm{N}$ & FAD & IAF & DAS & NSD & DPS & SF & SP & SG & $C L$ & GLI & TransDir & TransDif \\
\hline$G$ & 1.00 & & & & & & & & & & & & & & \\
\hline \multirow[t]{2}{*}{ dc } & 0.76 & 1.00 & & & & & & & & & & & & & \\
\hline & 0.001 & & & & & & & & & & & & & & \\
\hline \multirow[t]{2}{*}{ NSD } & -0.47 & -0.88 & 1.00 & & & & & & & & & & & & \\
\hline & 0.066 & 0.000 & & & & & & & & & & & & & \\
\hline \multirow[t]{2}{*}{ FAD } & 0.37 & 0.53 & -0.48 & 1.00 & & & & & & & & & & & \\
\hline & 0.157 & 0.035 & 0.061 & & & & & & & & & & & & \\
\hline \multirow[t]{2}{*}{ IAF } & -0.37 & -0.49 & 0.42 & -0.97 & 1.00 & & & & & & & & & & \\
\hline & 0.162 & 0.056 & 0.109 & 0.000 & & & & & & & & & & & \\
\hline \multirow[t]{2}{*}{ DAS } & 0.47 & 0.59 & -0.54 & 0.91 & -0.89 & 1.00 & & & & & & & & & \\
\hline & 0.068 & 0.017 & 0.031 & 0.000 & 0.000 & & & & & & & & & & \\
\hline \multirow[t]{2}{*}{ NSD } & 0.29 & 0.10 & 0.12 & 0.27 & -0.32 & 0.35 & 1.00 & & & & & & & & \\
\hline & 0.276 & 0.723 & 0.653 & 0.016 & 0.004 & 0.002 & & & & & & & & & \\
\hline \multirow[t]{2}{*}{ DPS } & 0.17 & 0.43 & -0.52 & 0.70 & -0.65 & 0.71 & -0.35 & 1.00 & & & & & & & \\
\hline & 0.540 & 0.095 & 0.041 & 0.000 & 0.000 & 0.000 & 0.001 & & & & & & & & \\
\hline \multirow[t]{2}{*}{ SF } & -0.23 & -0.39 & 0.47 & -0.74 & 0.70 & -0.78 & 0.16 & -0.85 & 1.00 & & & & & & \\
\hline & 0.382 & 0.133 & 0.064 & 0.000 & 0.000 & 0.000 & 0.167 & 0.000 & & & & & & & \\
\hline \multirow[t]{2}{*}{ SP } & 0.28 & 0.38 & -0.45 & 0.71 & -0.68 & 0.76 & -0.06 & 0.73 & -0.98 & 1.00 & & & & & \\
\hline & 0.303 & 0.141 & 0.078 & 0.000 & 0.000 & 0.000 & 0.607 & 0.000 & 0.000 & & & & & & \\
\hline \multirow[t]{2}{*}{ SG } & -0.01 & 0.21 & -0.37 & 0.58 & -0.54 & 0.62 & -0.34 & 0.82 & -0.85 & 0.77 & 1.00 & & & & \\
\hline & 0.956 & 0.438 & 0.153 & 0.000 & 0.000 & 0.000 & 0.002 & 0.000 & 0.000 & 0.000 & & & & & \\
\hline \multirow[t]{2}{*}{$C L$} & 0.13 & 0.45 & -0.46 & 0.44 & -0.39 & 0.39 & -0.38 & 0.79 & -0.39 & 0.22 & 0.39 & 1.00 & & & \\
\hline & 0.632 & 0.083 & 0.072 & 0.000 & 0.000 & 0.000 & 0.001 & 0.000 & 0.000 & 0.051 & 0.000 & & & & \\
\hline \multirow[t]{2}{*}{ GLI } & 0.36 & 0.50 & -0.47 & 0.95 & -0.94 & 0.95 & 0.26 & 0.75 & -0.76 & 0.72 & 0.63 & 0.46 & 1.00 & & \\
\hline & 0.176 & 0.050 & 0.069 & 0.000 & 0.000 & 0.000 & 0.020 & 0.000 & 0.000 & 0.000 & 0.000 & 0.000 & & & \\
\hline \multirow[t]{2}{*}{ TransDir } & 0.40 & 0.52 & -0.49 & 0.87 & -0.87 & 0.96 & 0.28 & 0.73 & -0.76 & 0.72 & 0.63 & 0.43 & 0.98 & 1.00 & \\
\hline & 0.120 & 0.040 & 0.056 & 0.000 & 0.000 & 0.000 & 0.013 & 0.000 & 0.000 & 0.000 & 0.000 & 0.000 & 0.000 & & \\
\hline \multirow[t]{2}{*}{ TransDif } & 0.30 & 0.47 & -0.44 & 0.98 & -0.97 & 0.89 & 0.23 & 0.72 & -0.73 & 0.68 & 0.59 & 0.47 & 0.97 & 0.90 & 1.00 \\
\hline & 0.262 & 0.069 & 0.091 & 0.000 & 0.000 & 0.000 & 0.044 & 0.000 & 0.000 & 0.000 & 0.000 & 0.000 & 0.000 & 0.000 & \\
\hline
\end{tabular}

$\mathrm{G}$ = área basal; $\mathrm{dc}$ = diametro cuadrático, $\mathrm{N}$ = densidad; FAD = fracción de apertura del dosel; IAF = índice de área foliar; DAS = duración acumulada diaria; NSD = haces de luz diarios; DPS = duración media de un haz de luz; SF = haces de luz "sunflecks"; SP = parches de luz; SG = claros de luz; CL = claros; GLI = índice de transmisión de luz; TransDiff = luz difusa transmitida; TransDir = luz directa transmitida. 

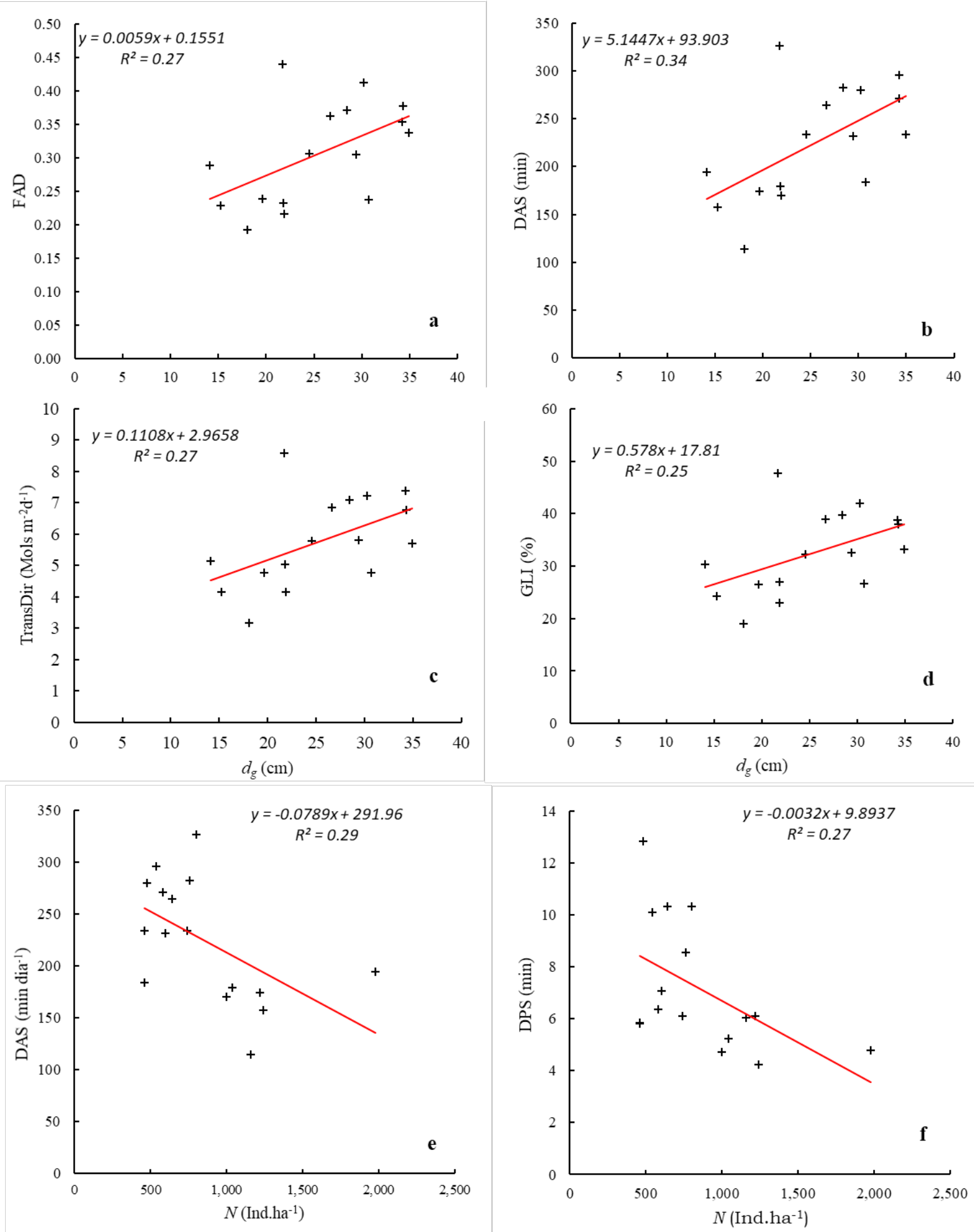

FIGURA 1. Relación entre el diámetro cuadrático (dc) con: a) fracción de apertura del dosel (FAD); b) duración acumulada de radiación (DAS); c) radiación directa transmitida (TransDir); y d) índice de transmisión de luz (GLI); y relación entre la densidad del rodal (N) con: e) duración acumulada promedio de radiación (DAS) y f) duración promedio de un haz de luz (DPS). 


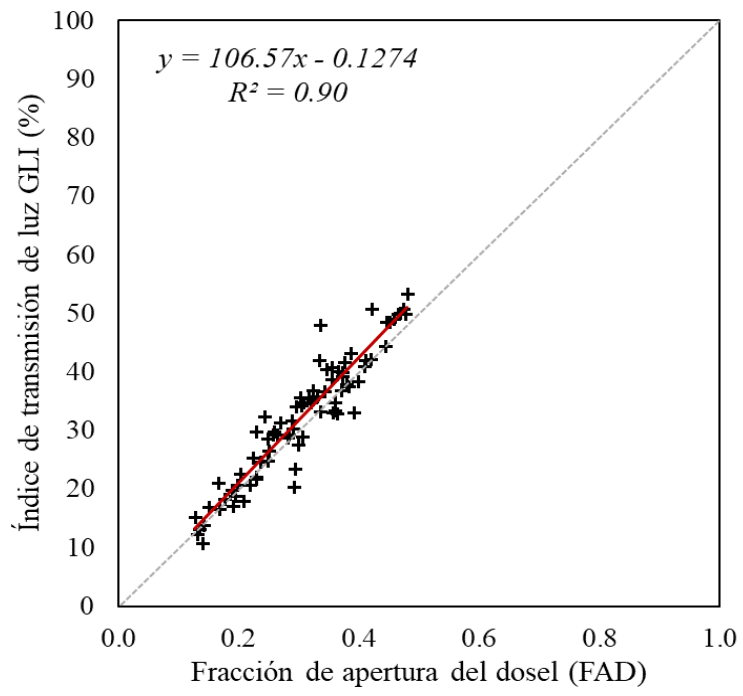

FIGURA 2. Relación entre el índice de transmisión de luz y la fracción de apertura del dosel.

La línea punteada indica la relación l:1, y la línea continua en color rojo corresponde a la ecuación de regresión lineal GLI = 106.5676 × FAD + 0.1274 (n $\left.=80 ; R^{2}=0.90\right)$
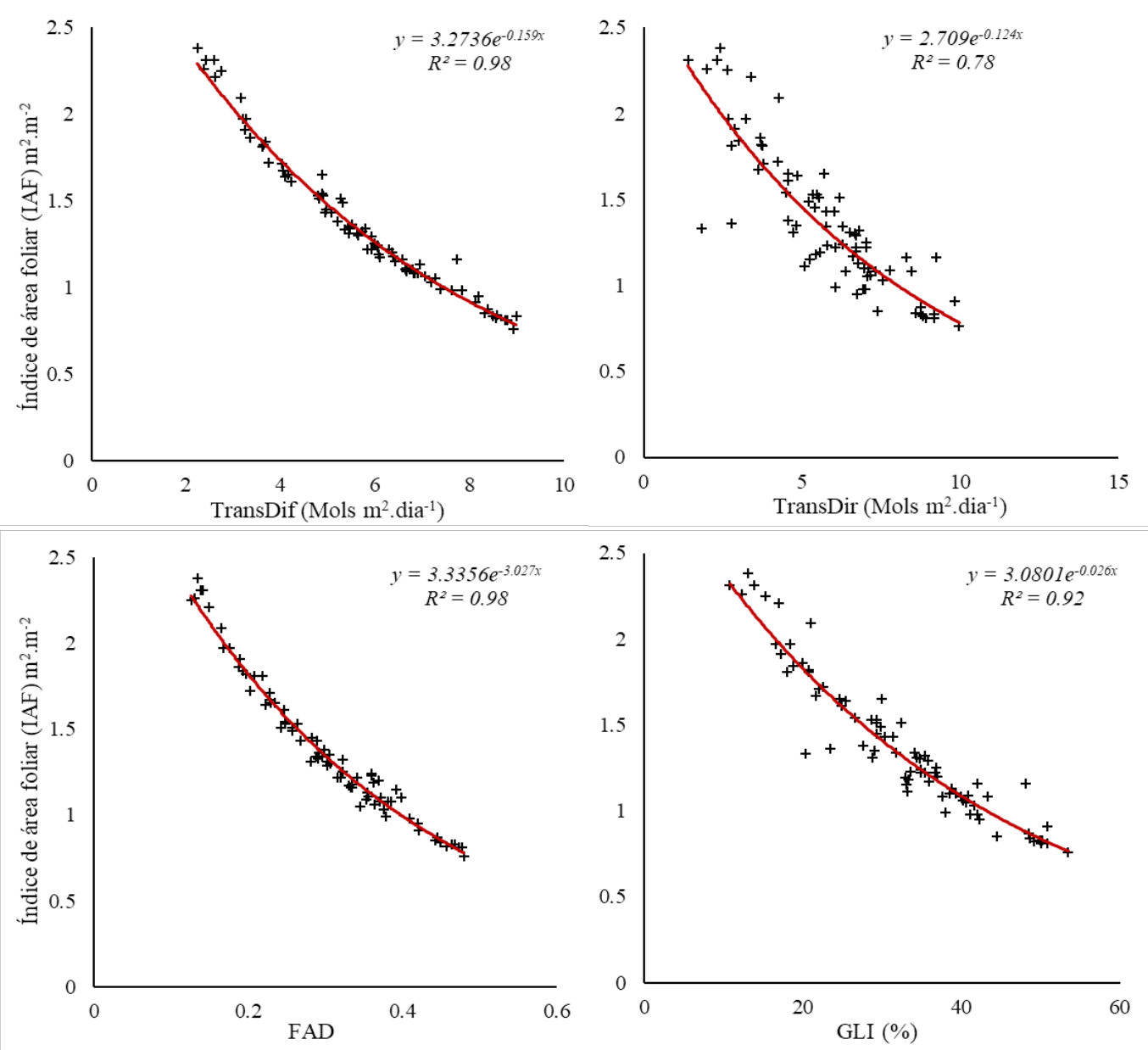

FIGURA 3. Relación entre el índice de área foliar (IAF) con a) radiación difusa transmitida a través del dosel (TransDif); b) radiación directa transmitida (TransDir); c) fracción de apertura del dosel (FAD); y d) índice de transmisión de luz GLI (\%). 

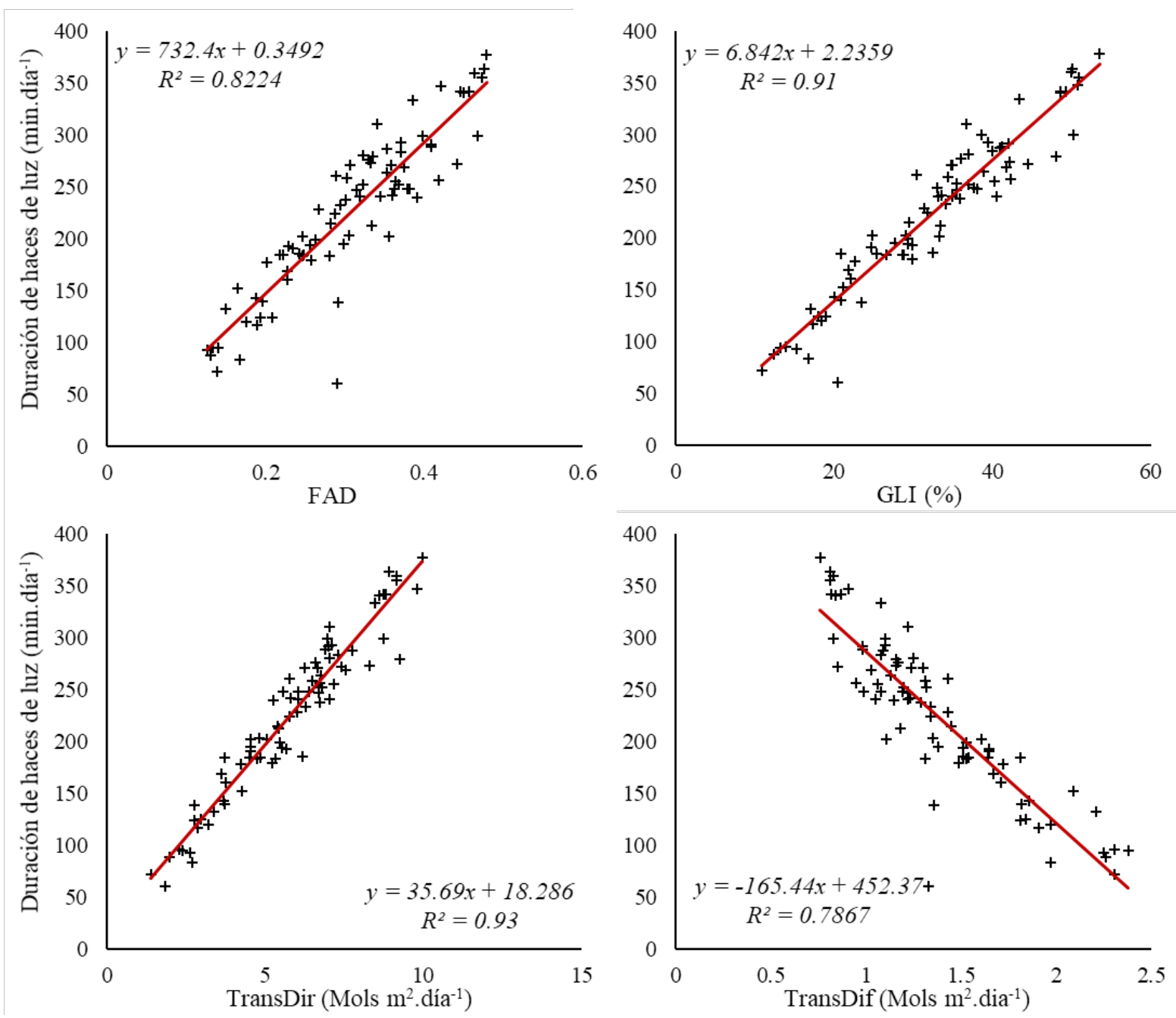

FIGURA 4. Relación entre la duración promedio acumulada de haces de luz por día en minutos (DAS) con: a) fracción de apertura del dosel (FAD); b) índice de transmisión de luz en porcentaje (GLI); c) radiación directa transmitida a través del dosel (TransDir); y d) índice de área foliar (IAF $\left.\mathrm{m}^{2} \mathrm{~m}^{-2}\right)$.

duración media de un haz de luz (DPS) tiene una relación negativa con el índice de área foliar (IAF) $\left(R^{2}=0.43, p<\right.$ 0.0001) (Fig. 5).

El análisis de distribución de frecuencias por clase de la duración de los haces de luz permite una mejor comprensión de la estructura del dosel (Smith, Sampson y Long, 1991) (Tabla 2). Los estadísticos obtenidos para el porcentaje del total de radiación solar directa incidente bajo el dosel (i.e. haces de luz, SF) son: media de $83.5 \% \pm 6.26 \%$, máximo y mínimo de $95.76 \%$ y $70.26 \%$, respectivamente, (C.V. $=7.52 \%)$; para los parches o manchas de luz (SP) fue de $15.10 \% \pm 5.20 \%$ con un máximo de $26.27 \%$ y mínimo de $4.23 \%$ (C.V. $=34.46 \%)$, mientras que los menores aportes al total de radiación directa presente al nivel del sotobosque fueron de las clases claros de luz (SG) y claros (CL) cuyos valores no cumplieron el supuesto de normalidad.

$\mathrm{El}$ análisis de regresión lineal mostró que la incidencia de haces o destellos de luz (SF), con duración menor a 8 min, se relaciona de manera negativa con FAD $\left(R^{2}=0.55\right)$ y con la transmisión de radiación GLI $\left(R^{2}=0.58\right)$, TransDir $\left(R^{2}=0.58\right)$ y TransDif $\left(R^{2}=0.53\right)$, y de manera positiva con el índice de área foliar (IAF) $\left(R^{2}=0.50\right)$ (Fig. 6). En el caso de los parches o manchas de luz, así como de los claros 
de luz, los cuales se relacionan de manera negativa con el índice de área foliar (valores de $r=-0.68$ y $r=-0.54$, respectivamente) y de forma positiva con la transmisión de radiación (GLI, TranDir y TransDif) y con el FAD, los resultados indican que para un dosel en el cual se incrementa la presencia de claros, de igual forma se incrementará la transmisión de luz a través de este, estableciéndose un dosel discontinuo en el cual los eventos lumínicos incrementarán su duración (Hardy et al., 2004; Marthews et al., 2008; Sapkota y Odén, 2009). Para la radiación solar directa proveniente de eventos lumínicos de más de 120 minutos de duración que inciden en el dosel forestal (claros, CL), se obtuvo una correlación débil $(r<$ $0.50)$ tanto con los parámetros de estructura del dosel como para aquellos relacionados con la transmisión de la radiación a través del dosel (Tabla 3 ).
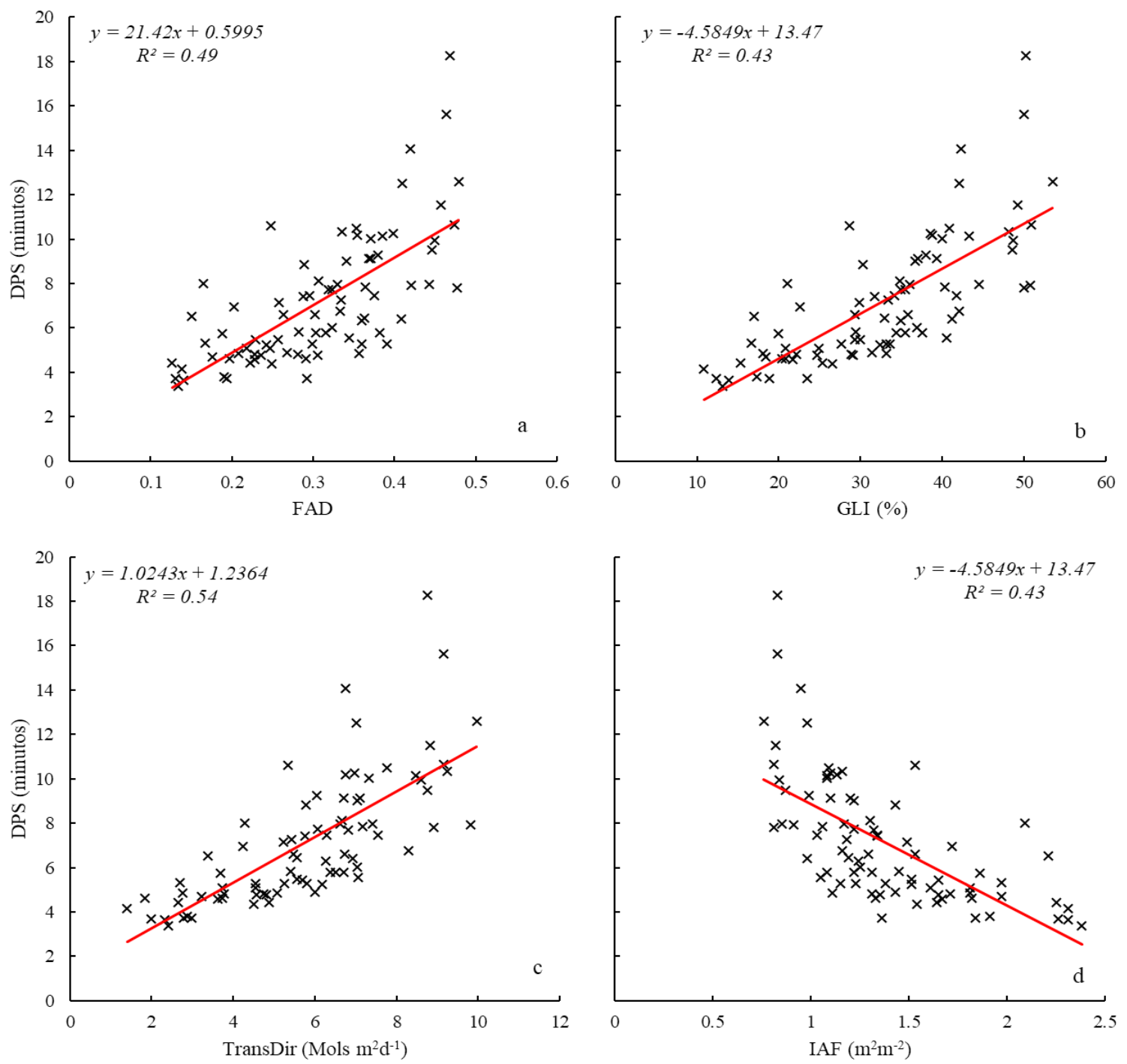

FIGURA 5. Relación existente entre la duración promedio de haces de luz (DPS) con: a) fracción de apertura del dosel (FAD); b) índice de transmisión de luz (GLI); c) radiación directa transmitida a través del dosel (TransDir); d) radiación difusa transmitida (TransDif) y e) índice de área foliar (IAF, $\left.\mathrm{m}^{2} \mathrm{~m}^{-2}\right)$. 

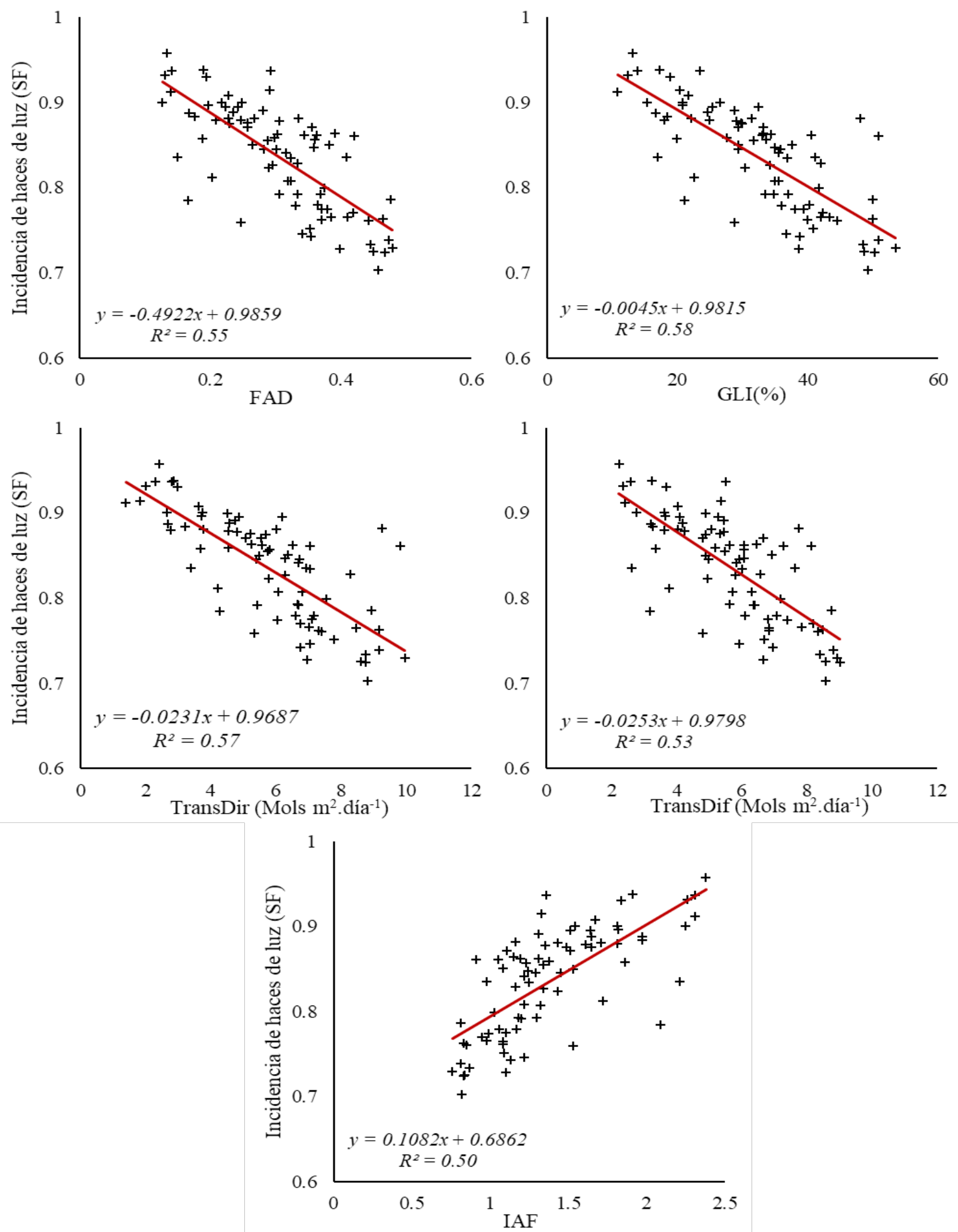

FIGURA 6. Relación entre la fracción de haces de luz (SF) con respecto del total de radiación directa presente bajo el dosel con: a) fracción de apertura del dosel (FAD), b) índice de transmisión de luz (GLI), c) radiación directa transmitida a través del dosel (TransDir), d) radiación difusa transmitida a través del dosel (TransDif) y e) índice de área foliar. 


\section{DISCUSIÓN}

Bajo el supuesto de que la composición y estructura de los rodales son determinantes de las comunidades de plantas presentes en el sotobosque (Fahey y Puettmann, 2007; Macdonald y Fenniak, 2007), se ha supuesto que existe influencia directa del dosel forestal sobre la riqueza y diversidad vegetal; por lo anterior, a partir de variaciones en la densidad, expresada en términos de la apertura, transmisión de luz, índice de área foliar, o bien, del régimen lumínico, se afectará de manera determinante a las comunidades vegetales que integran al sotobosque (Macdonald y Fenniak, 2007; Roberts y Gilliam, 1995).

Los parámetros de estructura del rodal obtenidos en este estudio muestran que un incremento en el diámetro cuadrático implica una reducción en la densidad, lo que significará un incremento en la apertura del dosel (Beaudet et al., 2011) y, en consecuencia, una mayor duración e incidencia de radiación directa a nivel del sotobosque. A raíz de lo anterior, aunque el diámetro cuadrático podría ser empleado como un estimador de la capacidad del dosel de transmitir la radiación incidente hacia el sotobosque, es evidente la necesidad de ampliar las estimaciones considerando las diferentes etapas de desarrollo de los rodales y poder expresar una conclusión más sólida a este respecto. Se encontró también una relación negativa entre la densidad del rodal y los parámetros de duración de eventos lumínicos (DAS y DPS), lo que indica que un incremento en la densidad del rodal disminuirá la variabilidad espacial de aperturas en el dosel (Beaudet $e t$ al., 2011), con un efecto importante en la duración de los haces de luz incidentes en el sotobosque. Este resultado es consistente con otros estudios en bosques de coníferas y boreales, donde se han encontrado relaciones negativas entre la densidad del rodal con disponibilidad y transmisión de luz bajo el dosel (e.g. radiación difusa) (Comeau, Heineman y Newsome, 2006; Comeau, 2001).

Respecto a la relación entre fracción de apertura del dosel e índice de transmisión de luz, el resultado concuerda con otros modelos de transmisión de luz en los cuales se ha utilizado a la cobertura como una variable importante para explicar la transmisión de luz a través del dosel forestal; por ejemplo, utilizando el densitómetro esférico se han obtenido valores de $R^{2}$ en un intervalo de 0.71 a 0.99 para bosques mezclados y puros de clima templado, Fagus y Quercus (Baudry, Charmetant, Collet, y Ponette, 2014), Quercus y Pinus (Buckley, 1999) y Betula (Comeau, Gendron y Letchford, 1998; Johansson, 1996); así como para bosques de clima tropical dominados por Cedrella, Cordia, Erythrina, Eucalyptus, Hieronyma, Musa, Pouteria y Psidium (Bellow y Nair, 2003). De igual manera, en modelos de transmisión de luz en los cuales se han usado fotografías hemisféricas para estimar la estructura del dosel, se han obtenido valores del coeficiente de determinación mayores a 0.60 para bosques de Pseudotsuga, Tsuga, Thuja y Alnus (Frazer et al., 2001), Acer, Betula y Fagus (Beaudet y Messier, 2002), plantaciones de Eucalyptus, Pinus, Cupressus, Grevilleay Juniperus (Yirdaw y Luukkanen, 2004), así como Liriodendron y Liquidambar (Lhotka y Loewenstein, 2006).

Estos resultados indican que un incremento en la disponibilidad de luz bajo el dosel forestal, dependerá básicamente del incremento de claros en el dosel (Canham, 1988; Gray, Spies y Easter, 2002; Lhotka y Loewenstein, 2006). Los valores para el IAF, estimados en este trabajo, se encuentran dentro del intervalo de valores obtenido por medio de otros métodos indirectos en bosques de Abies religiosa; se han obtenido valores que van de $3.0 \mathrm{~m}^{2} \mathrm{~m}^{-2}$ a 4.5 , para bosques densos, y de $1.0 \mathrm{~m}^{2} \mathrm{~m}^{-2}$ a $3.0 \mathrm{~m}^{2} \mathrm{~m}^{-2}$, para aquellos de menor densidad, usando datos radiométricos de imágenes de satélite ajustados mediante fotografías hemisféricas (Velasco, Champo, España y Baret, 2010), así como valores de IAF de entre $3.3 \mathrm{~m}^{2} \mathrm{~m}^{-2} \pm 0.18 \mathrm{~m}^{2} \mathrm{~m}^{-2} \mathrm{y}$ $2.85 \mathrm{~m}^{2} \mathrm{~m}^{-2} \pm 0.35 \mathrm{~m}^{2} \mathrm{~m}^{-2}$ obtenidos a partir del uso de sensores de radiación fotosintéticamente activa o PAR (Pérez-Suárez, Fenn, Cetina-Alcalá y Aldrete, 2008).

Los resultados obtenidos para la duración promedio acumulada de haces de luz (DAS) sugieren que, a medida que se incrementa la presencia de claros en el dosel, se aumenta la cantidad de luz directa bajo el mismo (Hardy et al., 2004), lo cual influye en el índice de transmisión de luz (Frazer et al., 1999), como resultado de un incremento en la duración promedio de los haces de luz que podrían alcanzar algún punto en el sotobosque (Lambers, Chapin y 
Pons, 2008). El índice de área foliar (IAF) presentó una correlación de -0.79 ( $p<0.0001)$ con DAS (Fig. 4) debido, principalmente, a que un incremento en el IAF representa a un dosel más denso (Chazdon y Pearcy, 1991), que da lugar a la presencia de aperturas de menor tamaño (Smith y Berry, 2013) y reduce la penetración de radiación directa a través del dosel, así como la duración de los haces de luz a nivel del sotobosque. La duración media de un haz de luz (DPS) mostró una relación negativa con el índice de área foliar (IAF) $\left(R^{2}=0.42, p<0.0001\right)$ (Fig. 5), manifestándose nuevamente que la estructura de las copas juega un rol importante en la dinámica del ambiente lumínico, así como en el comportamiento de los haces de luz que serán transmitidos a través del dosel y alcanzarán el sotobosque (Marthews et al., 2008). Así, cualquier incremento en la trasmisión de luz directa a través del dosel, ya sea por una mayor cantidad y tamaño de claros, o bien, por la disminución del follaje (es decir, del IAF), afectará de manera positiva a la duración de los haces de luz que alcanzarán el sotobosque.

Lo anterior es relevante porque se ha encontrado en el caso de Abies magnifica la incidencia de haces de luz de larga duración y alta densidad de flujo de fotones (i.e. mayores a $2000 \mu \mathrm{mol} \mathrm{m}{ }^{-2} \mathrm{~s}^{-1}$ ), que ocasionan fotoinhibición (Wong, Chen, Huang y Weng, 2012), en condiciones bajo dosel y con presencia de claros grandes; los haces de luz reducen tanto la germinación como la sobrevivencia, aunque también incrementan las tasas de reclutamiento en áreas con incidencia de haces de luz de corta duración y bajo doseles densos (Ustin, Woodward, Barbour y Hatfield, 1984; Way y Pearcy, 2012). Ustin et al. (1984) sugieren que el patrón de distribución agregado para plántulas de esta especie es el resultado de la influencia de la exposición prolongada a haces de luz con efecto en los lapsos de estrés hídrico y térmico a los cuales están sujetas las plántulas. La distribución de frecuencias muestra que más de 70\% de la radiación que ingresa en forma directa y se encuentra disponible en el sotobosque, se realiza a partir de haces de luz o pulsos de radiación directa de corta duración $(<8$ min) (Tabla 2). Esto coincide con evaluaciones de la contribución de los haces de luz, en los cuales se determinó que estos contribuyen entre $50 \%$ y $70 \%$ del total de la luz disponible en el sotobosque en bosques tropicales (Chazdon y Pearcy, 1991). En el caso de bosques de coníferas siempre verdes, la composición, estructura, así como la etapa de sucesión es muy heterogénea, por lo cual la caracterización de los regímenes de luz es difícil (Canham y Burbank, 1994; Chazdon et al., 1996). Sin embargo, se considera que la cantidad de radiación solar disponible bajo el dosel de bosques de coníferas perennes es mayor que aquella presente bajo el dosel de bosques tropicales siempre verdes, debido a que existen menos estratos de árboles y doseles moderadamente abiertos (Canham et al., 1990; Chazdon, 1988; Chen, 2014). Esta elevada presencia de eventos lumínicos de corta duración incrementa la heterogeneidad del ambiente lumínico a nivel del sotobosque (Chazdon y Pearcy, 1991), lo que provoca variaciones rápidas en la densidad del flujo de fotones (PFD), en duración, frecuencia e intensidad, las cuales afectan la respuesta fotosintética de las plantas a nivel del sotobosque e inducen respuestas metabólicas bioquímicas y fisiológicas de algunas especies (Pearcy, Krall y Sassenrath-Cole, 1996). En otros casos, existe un efecto negativo debido a fotoinhibición y reducción de la ganancia de carbono (Le Gouallec, Cornic, y Blanc, 1990; Leakey, Press y Scholes, 2003), o marchitez y daño en hojas por temperaturas elevadas (Chazdon y Pearcy, 1991; Wagner y McGraw, 2013).

En general, la fracción de apertura del dosel, el índice de área foliar, la cantidad de luz directa (TransDir) y la cantidad de luz difusa (TransDif) en los rodales analizados son muy variables (Tabla 2), lo cual indica que tanto la estructura como la transmisión de luz a través del dosel es muy heterogénea, dando como resultado un ambiente lumínico variable en el sotobosque de los rodales analizados.

\section{CONCLUSIONES}

El uso de FH para estimar el régimen lumínico en un rodal, o para estimar atributos estructurales del dosel, requiere de la ejecución meticulosa de una serie de pasos (i.e. selección de equipo, obtención y procesamiento de imágenes, 
aplicación de algoritmos), además de considerar posibles limitantes como la dependencia a condiciones meteorológicas adecuadas para la obtención de imágenes de calidad (i.e. días con nublado uniforme). También, es importante la limitada discriminación espectral, ya que los valores obtenidos para los colores rojo, verde y azul (RGB) no son considerados medidas precisas de radiación, comparadas con instrumentos especializados en espectrometría de luz. Además, se debe tener en cuenta que los valores obtenidos para el IAF a partir de FH están subestimados en comparación con métodos directos empleados para ello, y que es necesario considerar que la imagen obtenida es una representación simplificada en dos dimensiones del dosel, siendo este un complejo tridimensional. Es recomendable que el usuario se encuentre familiarizado con los modelos matemáticos empleados en el análisis, de tal manera que la aplicación así como la interpretación de los resultados del análisis de las FH sea el adecuado.

Los resultados obtenidos en este estudio indican que la transmisión de radiación solar hacia el sotobosque en los bosques de Abies religiosa estudiados se caracteriza por una gran variación espacial y temporal. Los parámetros de estructura del dosel -principalmente- y del rodal -en menor grado- explican, al menos en parte, la variación del régimen de radiación solar.

El mejor predictor para el índice de área foliar, radiación directa y radiación difusa disponible en el sotobosque y del índice de transmisión de luz del dosel fue la fracción de apertura del dosel, mientras que las estimaciones a partir de algún parámetro de la estructura del rodal mostraron una relación débil.

La estimación del índice de área foliar a partir de parámetros de transmisión de luz y estructura del dosel por medio del modelo Beer-Lambert, mostró que la relación existente entre los parámetros de radiación trasmitida (directa y difusa), apertura del dosel e índice de transmisión de luz del dosel se ajustan a un modelo de tipo exponencial, indicando que la transmisión de luz disminuirá siguiendo dicha tendencial al aumentar el área de intercepción del dosel, debido a un incremento en la cobertura y densidad de copas. El modelo de Beer-Lambert resulta ser adecuado para doseles simples y homogéneos, como el caso de rodales puros; sin embargo, investigaciones recientes indican que para doseles heterogéneos y complejos dicho modelo podría no proporcionar resultados satisfactorios y es necesario utilizar otro tipo de modelos (Forrester et. al, 2014). Los modelos de regresión ajustados para intentar explicar y estimar de manera sencilla los componentes del régimen y dinámica de la radiación solar presente en el sotobosque, a partir de parámetros de estructura del dosel, mostraron una relación moderada. Los parámetros de apertura el dosel e índice de transmisión de luz pueden ser usados para explicar buena parte de la variación en la duración y ración de la incidencia de haces de luz (e.g. duración media acumulada diaria, haces de luz "sunflecks", parches de luz "sunpatch" y claros de luz "sungap"). La capacidad de los parámetros de estructura del rodal (área basal, densidad y diámetro cuadrático) para estimar los componentes del régimen y dinámica de la radiación solar bajo el dosel fue pobre o nula.

\section{RECONOCIMIENTOS}

Al Consejo Nacional de Ciencia y Tecnología (Conacyt) por la beca otorgada para realizar estudios de postgrado del primer autor. Al Ing. León Jorge Castaños Martínez e Ing. Salvador Castro Zavala por el invaluable apoyo recibido para llevar a cabo esta investigación en la reserva forestal multifuncional "El Manantial” S.C.

\section{REFERENCIAS}

Bartemucci, P., Messier, C., Canham, C. D., Bartemucci, P., \& Canham, C. D. (2006). Overstory influences on light attenuation patterns and understory plant community diversity and composition in southern boreal forests of Quebec. Canadian Journal of Forest Research, 36, 2065-2079. doi: 10.1139/X06-088

Baudry, O., Charmetant, C., Collet, C., \& Ponette, Q. (2014). Estimating light climate in forest with the convex densiometer: Operator effect, geometry and relation to diffuse light. European Journal of Forest Research, 133(1), 101-110. doi: 10.1007/s10342-013-0746-6

Beaudet, M., Harvey, B. D., Messier, C., Coates, K. D., Poulin, J., Kneeshaw, D. D., ... Bergeron, Y. (2011). Managing understory light conditions in boreal mixedwoods through variation in the 
intensity and spatial pattern of harvest: A modelling approach. Forest Ecology and Management, 261(1), 84-94. doi: 10.1016/j.foreco.2010.09.033

Beaudet, M., \& Messier, C. (2002). Variation in canopy openness and light transmission following selection cutting in northern hardwood stands: An assessment based on hemispherical photographs. Agricultural and Forest Meteorology, 110(3), 217-228. doi: 10.1016/S0168-1923(01)00289-1

Bellow, J. G., \& Nair, P. K. R. (2003). Comparing common methods for assessing understorey light availability in shaded-perennial agroforestry systems. Agricultural and Forest Meteorology, 114, $197-$ 211.

Bonham, C. D. (2013). Measurements for terrestrial vegetation (2a ed.). West Sussex, UK: John Wiley \& Sons Inc.

Buckley, D. (1999). Practical field methods of estimating canopy cover, PAR, and LAI in Michigan oak and pine stands. Northern Journal of Applied Forestry, 16, 25-32.

Canham, C. D. (1988). An index for understory light levels in and aroung canopy gaps. Ecology, 69(5), 1634-1638. doi: 10.2307/1941664

Canham, C. D., \& Burbank, D. H. (1994). Causes and consequences of resource heterogeneity in forests: interspecific variation in light transmission by canopy trees. Canadian Journal of Forest Research, 24(2), 337-349.

Canham, C. D., Denslow, J. S., Platt, W. J., Runkle, J. R., Spies, T. A., \& White, P. S. (1990). Light regimes beneath closed canopies and tree-fall gaps in temperate and tropical forests. Canadian Journal of Forest Research, 20, 620-631.

Castaños, M. L. J., \& Castro, Z. S. (2014). Manejo Forestal Reserva Forestal Multifuncional, "El Manantial S.C.”: Conceptos, conductas y acciones. Zapopan, Jalisco: Comisión Nacional Forestal - Programa de las Naciones Unidas para el Desarrollo. doi: 10.1017/CBO9781107415324.004

Chazdon, R. L. (1988). Sunflecks and their importance to forest understorey plants. En M. Begon, A. H. Fitter, E. D. Ford, \& A. Macfadyen (Eds.), Advances in Ecological Research. London: Academic Press Inc. doi: 10.1016/S0065-2504(08)60179-8

Chazdon, R. L., \& Pearcy, R. W. (1991). The importance of sunflecks for forest understory plants. BioScience, 41(11), 760-766. doi: $10.2307 / 1311725$

Chazdon, R. L., Pearcy, R. W., Lee, D. W., \& Fetcher, N. (1996). Photosynthetic responses of tropical forest plants to contrasting light environments. En S. S. Mulkey, R. L. Chazdon, \& A. P. Smith (Eds.), Tropical forest plant ecophysiology (pp. 1-55). Boston, MA: Chapman \& Hall.
Chazdon, R. L., Pearcy, R. W., Lee, D. W., \& Fetcher, N. (1996). Photosynthetic Responses of Tropical Forest Plants to Contrasting Light Environments. En S. S. Mulkey, R. L. Chazdon, \& A. P. Smith (Eds.), Tropical Forest Plant Ecophysiology (pp. 5-55). Boston, MA: Springer US. doi: 10.1007/978-1-4613-1163-8_1

Chen, H. Y. H. (2014). Characteristics of light availability under forest canopies and its influences on photosynthesis of understory plants characteristics of light availability under forest canopies and its influences on photosynthesis of understory plants. Forestry Studies in China, 5(3)(January 2003), 54-62.

Chianucci, F., \& Cutini, A. (2013). Estimation of canopy properties in deciduous forests with digital hemispherical and cover photography. Agricultural and Forest Meteorology, 168, 130-139. doi: 10.1016/j.agrformet.2012.09.002

Comeau, P. G. (2001). Relationships between stand parameters and understorey light in boreal aspen stands. Journal of Ecosystems and Management, 1(2), 1-8.

Comeau, P. G., Gendron, F., \& Letchford, T. (1998). A comparison of several methods for estimating light under a paper birch mixedwood stand. Canadian Journal Of Forest Research Revue Canadienne De Recherche Forestiere, 28(12), 1843-1850. doi: 10.1139/x98-159

Comeau, P., Heineman, J., \& Newsome, T. (2006). Evaluation of relationships between understory light and aspen basal area in the British Columbia central interior, 226, 80-87. doi: 10.1016/j.foreco.2005.12.060

Denny, C. K., \& Nielsen, S. E. (2017). Spatial heterogeneity of the forest canopy scales with the heterogeneity of an understory shrub based on fractal analysis. Forests, 8(5). doi: 10.3390/f8050146

Fahey, R. T., \& Puettmann, K. J. (2007). Ground-layer disturbance and initial conditions influence gap partitioning of understorey vegetation. Journal of Ecology, 95(5), 1098-1109. doi: 10.1111/j.1365-2745.2007.01283.x

Organización de las Naciones Unidas para la Alimentación y la Agricultura - Organización de las Naciones Unidas para la Educación, la Ciencia y la Cultura [FAO-Unesco] (1998). Revised legend of FAO-UNESCO soil map of the world. International Soil Reference and Information Centre. Roma: FAO.

Forrester, D. I., Guisasola, R., Tang, X., Albrecht, A. T., Dong, T. L., \& le Maire, G. (2014). Using a stand-level model to predict light absorption in stands with vertically and horizontally heterogeneous canopies. Forest Ecosystems, 1(1), 1-19. doi: 10.1186/s40663-014-0017-0

Frazer, G. W., Canham, C. D., \& Lertzman, K. P. (1999). Gap Light Analyzer (GLA): Imaging software to extract canopy structure 
and gap light transmission indices from true-colour fisheye photographs, users manual and program documentation. Users Manual and Program Documentation, Version 2.0. Simon Fraser University, Burnaby, British Columbia, and the Institute of Ecosystem Studies, Millbrook, New York.

Frazer, G. W., Fournier, R. A., Trofymow, J. A., \& Hall, R. J. (2001). A comparison of digital and film fisheye photography for analysis of forest canopy structure and gap light transmission. Agricultural and Forest Meteorology, 109(4), 249-263. doi: 10.1016/S01681923(01)00274-X

Freese, F. (1976). Elementary Forest Sampling. Agriculture Handbook U.S Departement of Agriculture (Forest Service). doi: $10.1016 /$ j.foreco.2010.08.035

García, E. (1964). Modificaciones al sistema de clasificación climática de Köppen ( $5^{\mathrm{a}}$ ed). México, D.F.: Instituto de Geografía UNAM.

Gates, D. M. (1980). Solar Radiation. In Biophysical Ecology (pp. 96-147). New York, NY: Springer New York. doi: 10.1007/978-1-46126024-0_6

Gonsamo, A., D’odorico, P., \& Pellikka, P. (2013). Measuring fractional forest canopy element cover and openness - definitions and methodologies revisited. Oikos, 122(9), 1283-1291. doi: 10.1111/j.1600-0706.2013.00369.x

Gray, A. N., Spies, T. a, \& Easter, M. J. (2002). Microclimatic and soil moisture responses to gap formation in coastal Douglas-fir forests. Canadian Journal of Forest Research, 32(Tilman 1988), 332 343. doi: 10.1139/x01-200

Hale, S. E., Edwards, C., Mason, W. L., Price, M., \& Peace, A. (2009). Relationships between canopy transmittance and stand parameters in Sitka spruce and Scots pine stands in Britain. Forestry, 82(5), 503-513. doi: 10.1093/forestry/cpp020

Hardy, J. P., Melloh, R., Koenig, G., Marks, D., Winstral, A., Pomeroy, J. W., \& Link, T. (2004). Solar radiation transmission through conifer canopies. Agricultural and Forest Meteorology, 126(3-4), 257 270. doi: 10.1016/j.agrformet.2004.06.012

Hu, L., Yan, B., Wu, X., \& Li, J. (2010). Calculation method for sunshine duration in canopy gaps and its application in analyzing gap light regimes. Forest Ecology and Management, 259(3), 350-359.

Jennings, S. B., Brown, N. D., \& Sheil, D. (1999). Assessing forest canopies and understorey illumination: canopy closure, canopy cover and other measures. Forestry, 72(1), 59-74. doi: $10.1093 /$ forestry/72.1.59

Kopp, G., \& Lean, J. L. (2011). A new, lower value of total solar irradiance: Evidence and climate significance. Geophysical Research Letters, 38(1), 1-7. doi: 10.1029/2010GL045777
Lambers, H., Chapin, F. S., \& Pons, T. L. (2008). Plant Physiological Ecology (2a ed). New York: Springer.

Larsen, D. R., \& Kershaw, J. A. (1996). Influence of canopy structure assumptions on predictions from Beer's law. A comparison of deterministic and stochastic simulations. Agricultural and Forest Meteorology. doi: 10.1016/0168-1923(95)02307-0

Le Gouallec, J. L., Cornic, G., \& Blanc, P. (1990). Relations betweensunfleck sequences and photoinhibition of photosynthesis in atropical rain-forest understorey herb. American Journal of Botany, 77, 999-1006.

Leakey, A. D. B., Press, M. C., \& Scholes, J. D. (2003). High-temperature inhibition of photosynthesis is greater under sun flecks than uniform irradiance in a tropical rain forest tree seedling. Plant, Cell and Environment, 26, 1681-1690.

Leblanc, S. G., Chen, J. M., Fernandes, R., Deering, D. W., \& Conley, A. (2005). Methodology comparison for canopy structure parameters extraction from digital hemispherical photography in boreal forests. Agricultural and Forest Meteorology, 129(3-4), 187207.

Lhotka, J. M., \& Loewenstein, E. F. (2006). Indirect measures for characterizing light along a gradient of mixed-hardwood riparian forest canopy structures. Forest Ecology and Management, 226(1-3), 310-318. doi: 10.1016/j.foreco.2006.01.043

Lieffers, V. J., Messier, C., Stadt, K. J., Gendron, F., \& Comeau, P. G. (1999). Predicting and managing light in the understory of boreal forests. Canadian Journal of Forest Research, 29(6), 796-811. doi: 10.1139/x98-165

Ligot, G., Balandier, P., Courbaud, B., Jonard, M., Kneeshaw, D., \& Claessens, H. (2014). Managing understory light to maintain a mixture of species with different shade tolerance. Forest Ecology and Management, 327. doi: 10.1016/j.foreco.2014.05.010

López-Sandoval, J. A., López-Mata, L., Cruz-Cárdenas, G., Vibrans, H., Vargas, O., \& Martínez, M. (2015). Modelado de los factores ambientales que determinan la distribución de especies sinantrópicas de Physalis. Botanical Sciences, 93(4), 755-764. doi: 10.17129/botsci.192

Macdonald, S. E., \& Fenniak, T. E. (2007). Understory plant communities of boreal mixedwood forests in western Canada: Natural patterns and response to variable-retention harvesting. Forest Ecology and Management, 242(1), 34-48. doi: 10.1016/j.foreco.2007.01.029

Marthews, T. R., Burslem, D. F. R. P., Phillips, R. T., \& Mullins, C. E. (2008). Modelling Direct Radiation and Canopy Gap Regimes in Tropical Forests. Biotropica, 40(6), 676-685. 
Messier, C., Parent, S., \& Bergeron, Y. (1998). Effects of Overstory and Understory Vegetation on the Understory Light Environment in Mixed Boreal Forests. Journal of Vegetation Science, 9(4), 511. doi: $10.2307 / 3237266$

Monsi, M., \& Saeki, T. (2005). On the Factor Light in Plant Communities and its Importance for Matter Production. Annals of Botany, 95(3), 549-567. doi: 10.1093/aob/mci052

Muenchen, R. A., \& Hilbe, J. M. (2010). Statistics and Computing R for Stata Users. Springer New York.

Nackaerts, K., Coppin, P., Muys, B., \& Hermy, M. (2000). Sampling methodology for LAI measurements with LAI-2000 in small forest stands. Agricultural and Forest Meteorology, 101(4), 247-250. doi: 10.1016/S0168-1923(00)00090-3

Nobis, M., \& Hunziker, U. (2005). Automatic thresholding for hemispherical canopy-photographs based on edge detection. Agricultural and Forest Meteorology, 128(3-4), 243-250. doi: 10.1016/j.agrformet.2004.10.002

Papaioannou, G., Nikolidakis, G., Asimakopoulus, D., \& Retalis, D. (1996). Photosynthetically active radiation in Athens. Agricultural and Forest Meteorology, 81(1972), 287-298.

Pearcy, R. W., Krall, J. P., \& Sassenrath-Cole, G. F. (1996). Photosynthesis in Fluctuating Light Environments. In N. R. Baker (Ed.), Photosynthesis and the Environment (pp. 321-346). The Netherlands: Kluwer Academic Publishers.

Pekin, B., \& Macfarlane, C. (2009). Measurement of crown cover and leaf area index using digital cover photography and its application to remote sensing. Remote Sensing, 1(4), 1298-1320. doi: $10.3390 / \mathrm{rs} 1041298$

Pérez-Suárez, M., Fenn, M. E., Cetina-Alcalá, V. M., \& Aldrete, A. (2008). The effects of canopy cover on throughfall and soil chemistry in two forest sites in the México City air basin. Atmosfera, 21(1), 83-100.

Promis, A., Schindler, D., Reif, A., \& Cruz, G. (2009). Solar radiation transmission in and around canopy gaps in an uneven-aged Nothofagus betuloides forest. International Journal of Biometeorology, 53(4), 355-367. doi: 10.1007/s00484-009-0222-7

Roberts, M. R., \& Gilliam, F. S. (1995). Patterns and Mechanisms of Plant Diversity in Forested Ecosystems: Implications for Forest Management. Ecological Applications. doi: 10.2307/2269348

Sapkota, I. P., \& Odén, P. C. (2009). Gap characteristics and their effects on regeneration, dominance and early growth of woody species. Journal of Plant Ecology, 2(1), 21-29. doi: 10.1093/jpe/rtp004
Scanga, S. E. (2014). Population dynamics in canopy gaps: Nonlinear response to variable light regimes by an understory plant. Plant Ecology, 215(8), 927-935. doi: 10.1007/s11258-014-0344-9

Schleppi, P., \& Paquette, A. (2017). Hemispherical Photography in Forest Science: Theory, Methods, Applications. En R. A. Fournier \& R. J. Hall (Eds.), Managing Forest Ecosystems (Vol. 28, pp. 15-53). Dordrecht, Netherlands: Springer.

Schreuder, H. T., Ernst, R., \& Ramirez-Maldonado, H. (2004). Statistical Techniques for Sampling and Monitoring Natural Resources. Agriculture, RMRS-126(April), 111. Retrieved from http://www.treesearch.fs.fed.us/pubs/6287

Seidel, D., Fleck, S., Leuschner, C., \& Hammett, T. (2011). Review of ground-based methods to measure the distribution of biomass in forest canopies. Annals of Forest Science, 68(2), 225-244. doi: $10.1007 /$ s13595-011-0040-z

Smith, F. W., Sampson, D. A., \& Long, J. N. (1991). Comparison of Leaf Area Index Estimates from Tree Allometrics and Measured Light Interception. Forest Science, 37(6), 1682-1688.

Smith, W. K., \& Berry, Z. C. (2013). Sunflecks ? Tree Physiology, (33), 233 237. doi: $10.1093 /$ treephys/tpt005

Sonohat, G., Balandier, P., \& Ruchaud, F. (2004). Predicting solar radiation transmittance in the understory of even-aged coniferous stands in temperate forests. Annals of Forest Science, 61 (7), 629-641.

Ustin, S. L., Woodward, R. A., Barbour, M. G., \& Hatfield, J. L. (1984). Relationships between sunfleck dynamics and red fir seedling distribution. Ecology, (65), 1420-1428.

Velasco, S., Champo, O., España, M. L., \& Baret, F. (2010). Estimación del índice de área foliar en la reserva de la Biósfera Mariposa Monarca. Revista Fitotecnia Mexicana, 33(2), 169-174.

Venables, W. D., \& Smith, D. M. (2017). An Introduction to R. doi: 10.1016/B978-0-12-381308-4.00001-7

Wagner, A., \& McGraw, J. B. (2013). Sunfleck effects on physiology, growth, and local demography of American ginseng (Panax quinquefolius L.). Forest Ecology and Management, 291, 220-227. doi: 10.1016/j.foreco.2012.11.038

Way, D. A., \& Pearcy, R. W. (2012). Sunflecks in trees and forests: From photosynthetic physiology to global change biology. Tree Physiology, 32(9), 1066-1081. doi: 10.1093/treephys/tps064

Webster, C., Rutter, N., Zahner, F., \& Jonas, T. (2016). Measurement of Incoming Radiation below Forest Canopies: A Comparison of Different Radiometer Configurations. Journal of Hydrometeorology, 17(3), 853-864. doi: 10.1175/JHM-D-15-0125.1 
Plateros-Gastélum et $\boldsymbol{a l}$. Disponibilidad de luz bajo dosel

Wong, S. L., Chen, C. W., Huang, H. W., \& Weng, J. H. (2012). Using combined measurements for comparison of light induction of stomatal conductance electron transport rate and $\mathrm{CO} 2$ fixation in woody and fern species adapted to different light regimes. Tree Physiology, (32), 535-544.

Yirdaw, E., \& Luukkanen, O. (2004). Photosynthetically active radiation transmittance of forest plantation canopies in the Ethiopian highlands. Forest Ecology and Management, 188(1-3), 17-24. doi: 10.1016/j.foreco.2003.07.024

Zhang, Y., Chen, J. M., \& Miller, J. R. (2005). Determining digital hemispherical photograph exposure for leaf area index estimation. Agricultural and Forest Meteorology, 133, 166-181.
Manuscrito recibido el 11 de febrero de 2018

Aceptado el 17 de julio de 2018

Publicado el 4 de diciembre de 2018

Este documento se debe citar como:

Plateros-Gastélum, P. A., Reyes-Hernández, V. J., VelázquezMartínez, A., Hernández-de la Rosa, P., \& Campos-Ángeles, G. V. (2018). Disponibilidad de luz bajo dosel en rodales de Abies religiosa. Madera y Bosques, 24(3), e2431711. doi: 10.21829/myb.2018.2431711

Madera y Bosques por Instituto de Ecología, A.C. se distribuye bajo una Licencia Creative Commons Atribución-NoComercialCompartirlgual 4.0 Internacional. 
APÉNDICE. Ejemplos de las fotografías hemisféricas utilizadas en el estudio para cada rodal analizado

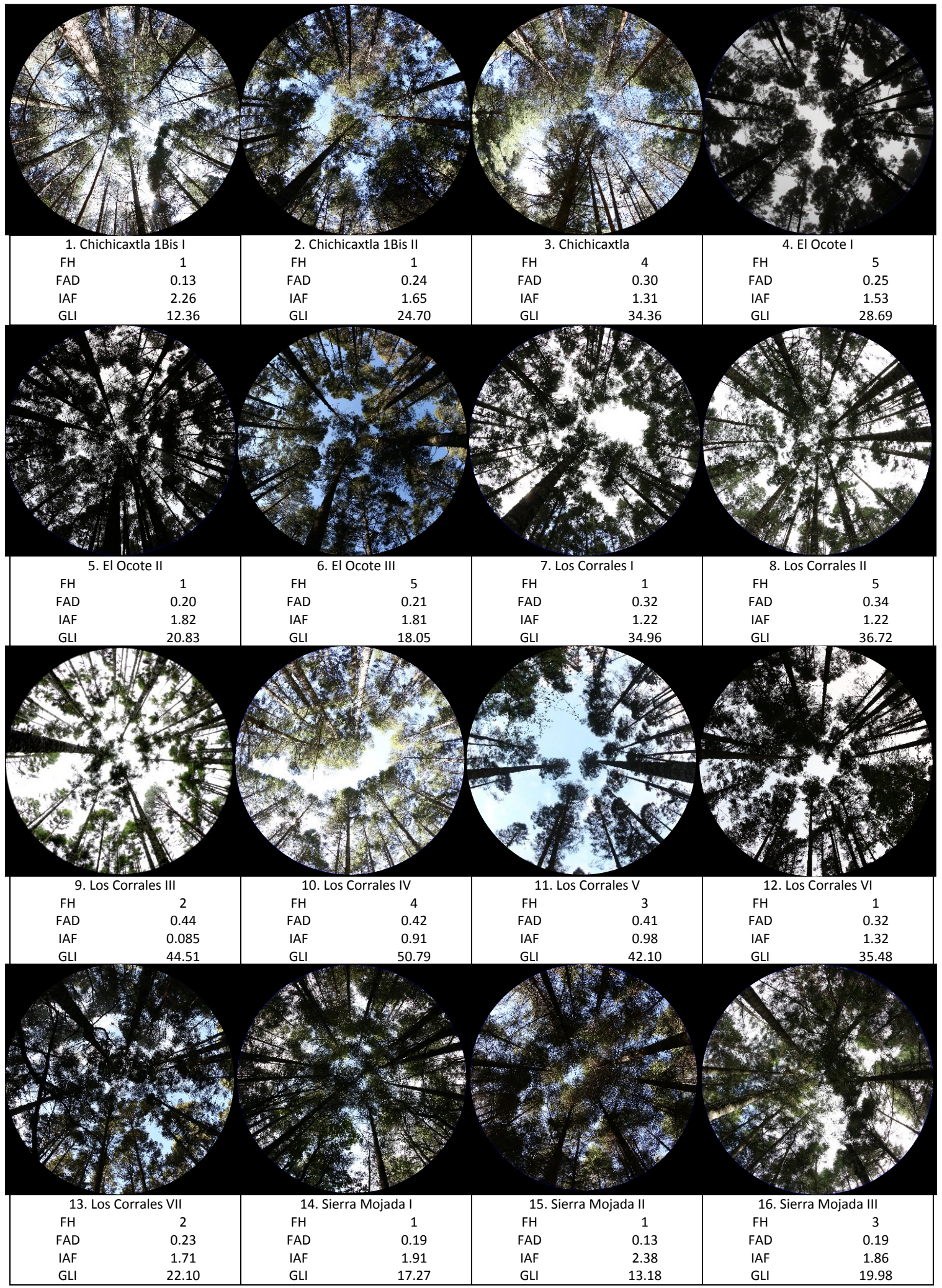

FH: número de fotografía hemisférica dentro de la parcela; FAD: fracción de apertura del dosel; IAF: índice de área foliar; GLI: índice de transmisión de luz. 